Meta

Journal des tradlucteurs

Translators' Journal

\title{
Les sports « aquatiques " pèchent-ils en eau trouble ?
}

\section{Robert Dubuc}

Volume 18, numéro 4, décembre 1973

URI : https://id.erudit.org/iderudit/002660ar

DOI : https://doi.org/10.7202/002660ar

Aller au sommaire du numéro

Éditeur(s)

Les Presses de l'Université de Montréal

ISSN

0026-0452 (imprimé)

1492-1421 (numérique)

Découvrir la revue

Citer cet article

Dubuc, R. (1973). Les sports « aquatiques " pèchent-ils en eau trouble ? Meta, 18(4), 370-371. https://doi.org/10.7202/002660ar d'utilisation que vous pouvez consulter en ligne.

https://apropos.erudit.org/fr/usagers/politique-dutilisation/ 


\section{LES SPORTS “AQUATIQUES” PËCHENT-ILS EN EAU 'TROUBLE?}

Pour caractériser les activités de loisirs reliées à l'eau, on avait virtuellement le choix en français entre deux adjectifs : aquatique et nautique. Au sens propre, aucun de ces adjectifs, toutefois, ne se prêtait facilement à pareille extension de sens. L'adjectif aquatique se dit proprement de ce «qui croît, vit dans l'eau ou au bord de l'eau ${ }^{1} \gg$. Ce sens, plutôt biologique, de l'adjectif aquatique semble en avoir gêné l'extension à d'autres domaines. Quoique rien ne justifie en soi cette fixation de sens, il semble bien que l'usage français l'ait respectée. On ne trouve que de façon exceptionnelle en français l'adjectif aquatique qualifiant un terme de sport. Au Canada, au contraire, l'adjectif aquatique (peut-être sous l'influence de l'anglais water) a connu une grande vogue au point d'évincer l'adjectif nautique,

12. Université Laval, Annuaire général 1971-1972, no 115, Québec, 1971, p. 121.

13. Georges Mounin, les Problèmes théoriques de la traduction, Paris, Gallimard, 1963, p. 73.

1. Paul Robert, le Petit Robert, Paris, 1969, p. 81. 
expression déjà pourtant bien en place. Ainsi, on parle ici de «ski aquatique », de «ballet aquatique », «sports aquatiques » et aussi, par ricochet, de « sécurité aquatique ». Cet usage n'a rien en lui-même de répréhensible, sauf qu'il est régional. En français international, c'est l'adjectif nautique qui a connu cette extension.

Au départ, cet adjectif est intimement lié à la navigation. Il se disait de tout ce qui touche à la navigation. Or, à l'ère des loisirs, il s'est développé autour de la navigation toute une série de sports qui lui ont été associés : le ski sur l'eau, le surfing et divers jeux faits sur l'eau ont été qualifiés de nautiques. Ces sports, reliés plus ou moins directement à la navigation, ont, pour ainsi dire, déteint sur les autres sports qui se pratiquaient dans l'eau mais qui n'avaient aucun rapport avec la navigation. C'est ainsi que le Grand Larousse encyclopédique ${ }^{2}$ et l'encyclopédie Clartés ${ }^{3}$ classent parmi les sports nautiques non seulement le ski, le yachting mais encore la natation, les plongeons, le sauvetage et le water-polo, qui n'ont rien à voir avec la navigation.

Quoi qu'en pensent les étymologistes, il semble bien que l'usage ait opté pour nautique plutôt que pour aquatique lorsqu'il s'agit de désigner ce qui est relatif aux activités sportives où l'eau joue un rôle prépondérant. Ainsi l'Encyclopédie des sports de Larousse qualifie le surf-riding d' "exercice nautique ${ }^{4}$ ». Le même ouvrage parle de «la meilleure équipe française des ballets nautiques ${ }^{5}$ ». Dans un autre ouvrage, Jean Dauven parle encore du « sauvetage nautique d'un mannequin immergé ${ }^{6}$ ».

Il reste difficile d'aller à l'encontre d'un usage qui semble passablement généralisé. Si l'on croit que notre français a tout avantage a être universel plutôt que local, il y a tout lieu, jusqu'à preuve du contraire, de parler de sports nautiques, de ski nautique, de ballet nautique, même si la navigation n'y trouve pas son compte. Et quant à la sécurité qui doit régir l'exercice de ces sports, elle devrait elle aussi être « nautique », si l'on veut être logique, n'en déplaise à la CroixRouge et aux autres croix qui pèsent sur notre langue.

ROBERT DUBUC 